\title{
Research Paper \\ Study the Factors and Policies Affecting Labor Employment
}

\author{
Farzaneh Khalili $^{1}$
}

1. Assistant Professor of Economics, Department of Economics, Faculty of Humanities, Abhar Branch, Islamic Azad University, Abhar, Iran.

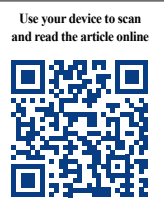

Cftation: Khalili F. (2019). [Evaluation of Factors and Policies Affecting Labor Employment (Persian)]. Quarterly Journal of the Macro and Strategic Policies, 7(3), 372-395. https://doi. org/10.32598/JMSP.7.3.3

\section{https://doi.org/10.32598/JMSP.7.3.3}

Received: 23 Nov 2017

Accepted: 24 Jun 2018

Available Online: 01 Oct 2019

Key words:

Resistance economy, Employment, Oil revenues, Trade openness, ARDL

\begin{abstract}
Considering the issue of unemployment and recession in recent years, the year 2017 was named "Resistance Economy, Production-Employment" by the Supreme Leader. Therefore, employment is one of the key indicators of resistance economy. In this regard, evaluating labor employment patterns, in order to identify the factors affecting it, is the most vital challenge for the implementation of the resistance economy. This research first presents general concepts and examines the theoretical foundations and literature of the factors affecting the resistance economy index (labor employment) and then by referring to variables such as minimum wage (policy-making variable), real GDP, real oil revenues, capital stock, foreign direct investment, and degree of business openness, attempts to explain the resistance economy index. The model estimation has been carried out by Autoregressive Distributed Lag (ARDL) method, and the Vector Autoregressive (VAR) model has been used to investigate the shocks for annual data of 1980-2015. The results showed that in the short run, GDP, capital stock, oil revenues, foreign direct investment and trade openness have a positive effect on the resistance economy index. However, the minimum wage with a lag period has a negative and significant effect on the index, which also holds true for the long term. Finally, it has been shown that the adverse effects of some shocks on resilience economy index will remain for many years to come.

JJEL Classification: C22, E24, J21, J24, J54, M51
\end{abstract}

* Corresponding Author:

Farzaneh Khalili, PhD.

Address: Department of Economics, Faculty of Humanities, Abhar Branch, Islamic Azad University, Abhar, Iran.

Tel: +98 (914) 1637405

E-mail: farzaneh_khalili2001@yahoo.com 


\title{
بررسى عوامل و سياستهاى مؤثر بر اشتغال ثيروى كار
}

فرزانه خليلى'

\author{
ا. استاديار تروه اقتصاد، دانشكده علوم انسانى، واحد ابهر، دانشكاه آزاد اسلامي، ابهر، ايران.
}

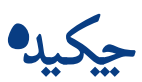

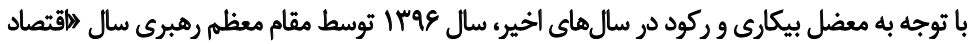

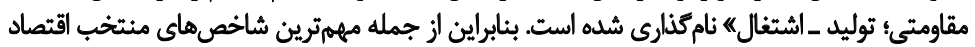

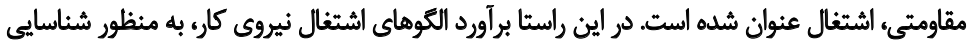

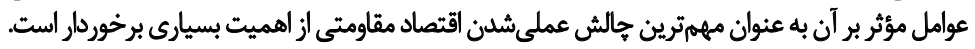

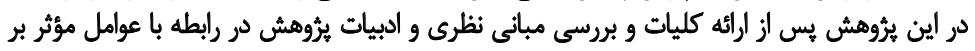

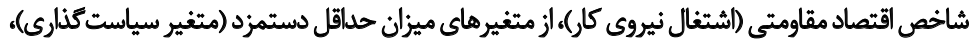

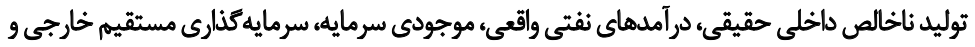

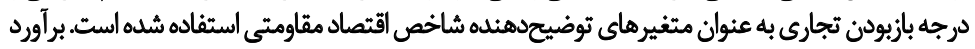

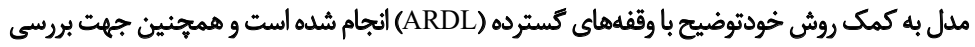

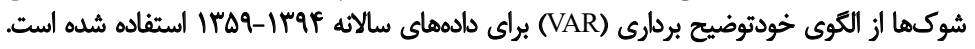

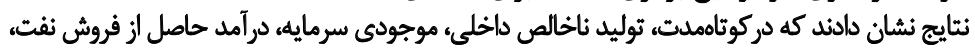

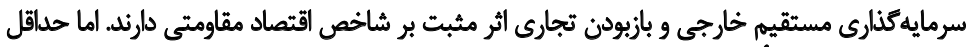

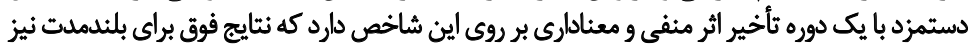

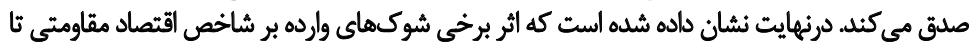
ساليان طولانى باقى خواهد ماند. طبقهبندى C22, E24, J21, J24, J54, M51 : JEL

\author{
تاريخ دريافت: ب. آذر و9 با

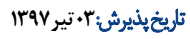

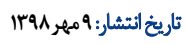

:Dojlguls

اقتصاد مقاومتى، اشتغال، درآهدهاي مقاوني، نفتى، بازبودن تجارى،

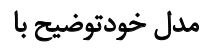
وقففهاي كسترده
\end{abstract}

\section{* نويسنده مسئول:}

دكثر فرزانه خليلي

نشاني: ابهر، دائشكاه آزاد اسلامي، دانشكده علوم انساني، كروه اقتصاد. تلفن: بست الكترونيكى: farzaneh_khalili2001@yahoo.com 


\section{dalo}

موضوع بيكارى، در سالهاى اخير يكى از معضلات اساسى كشور بوده است، به طورى كه طبق تأكيد مقام

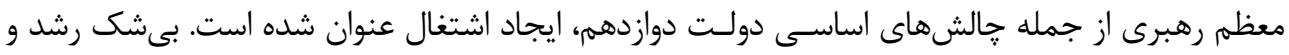

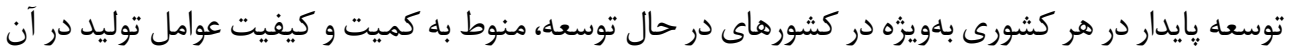

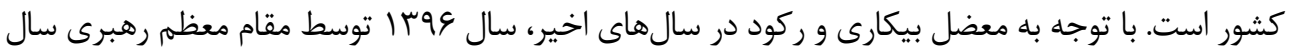

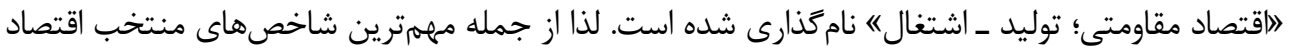

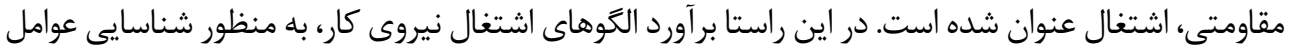

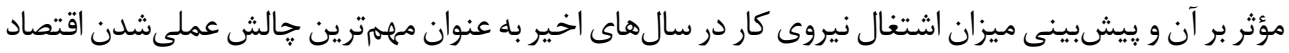

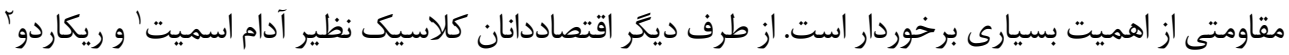

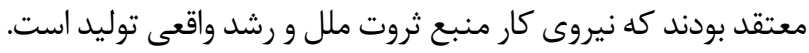

رهبر انقلاب اسلامى، حضرت آيتالله خامنهاى نخستينبار اصطلاح اقتصاد مقاومتى را در ديدار جمعى از

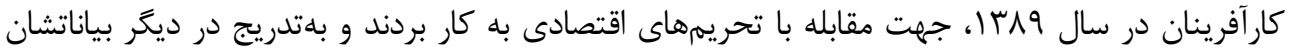

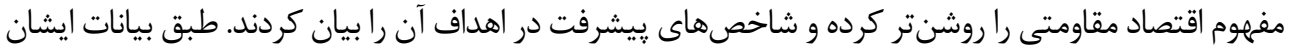

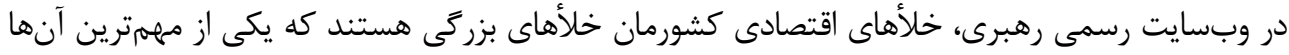

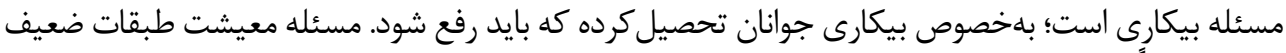

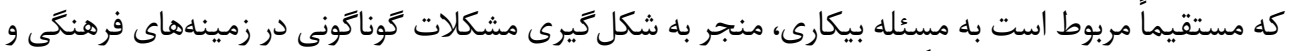

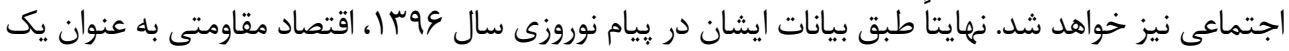

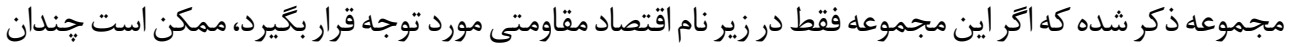

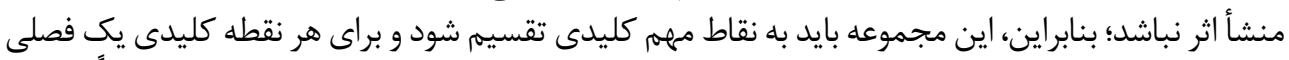

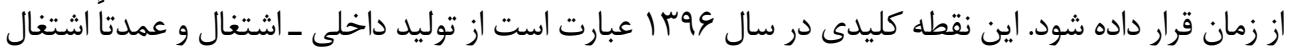

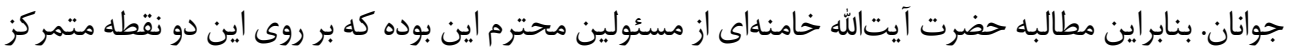

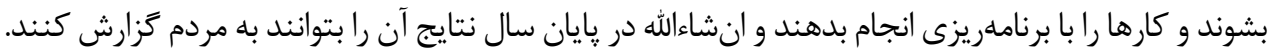
هر سال تعدادى نيروى كار جديد، وارد بازار كار مى شوند كه بايد براى آنها مشاغل جديد ايجاد شود. لذا بــه

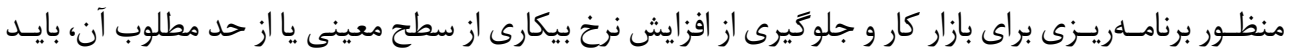

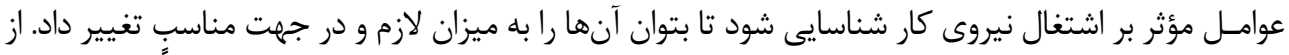

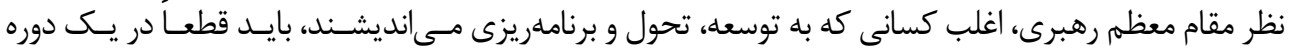
بلندمدت، درباره يِيشبينى منابع انسانى تفكر كنند (متقى،

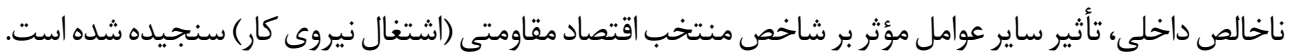


ا ـ إبيات موضوع

\section{|- - (. تجليل رويكرد اقتصاد مقاومثي}

براى تحليل اقتصاد مقاومتى دو رويكرد وجود دارد: رويكرد اول، رويكرد مديريت ريسك است؛ در اين رويكرد

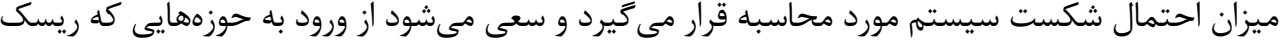

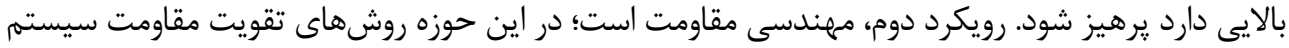
و همجنين ايجاد انعطاف يذيرى بيشتر در برابر تكانهها مورد مطالعه قرار مئى

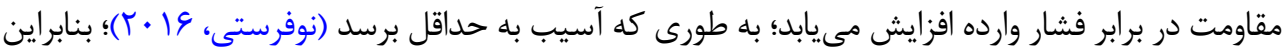

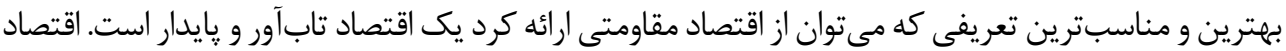

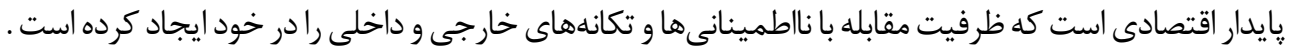

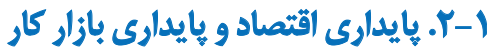

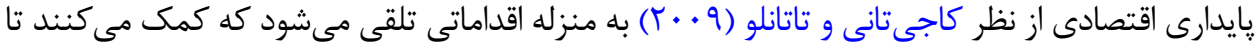

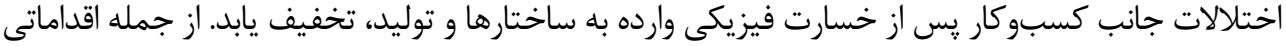

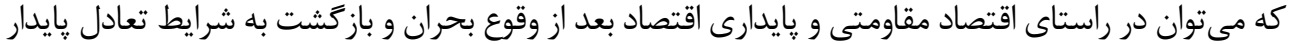

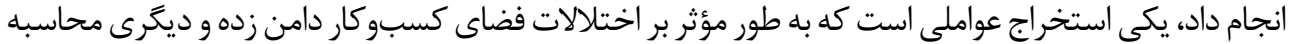

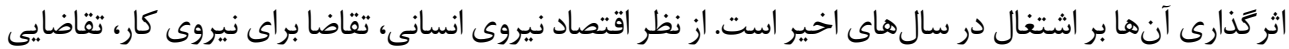

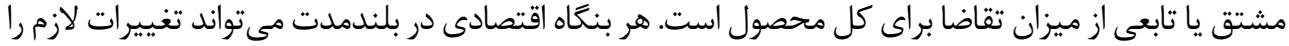

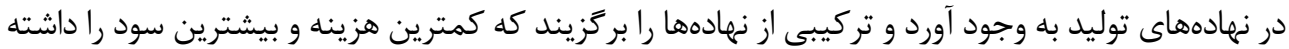

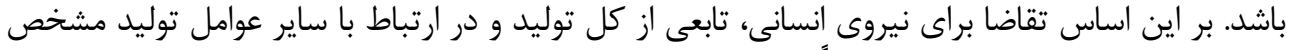

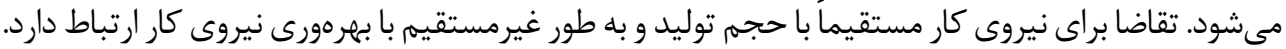

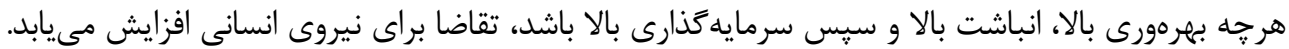

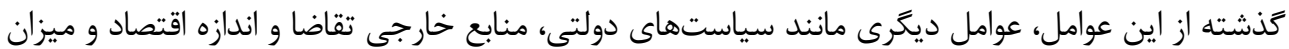

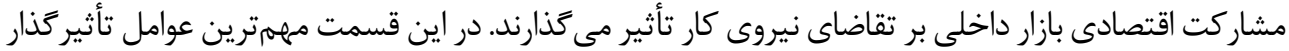

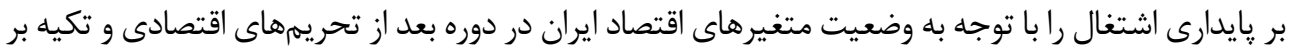

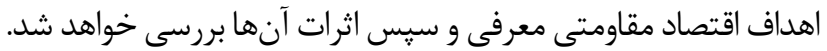

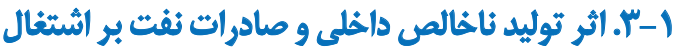

بيكارى ادوارى عبارت از بيكارىاى است كه به دليل كاهش سطح و حجم فعاليتهاى اقتصادى و بههمخوردن

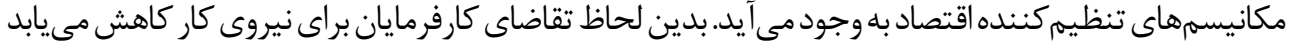

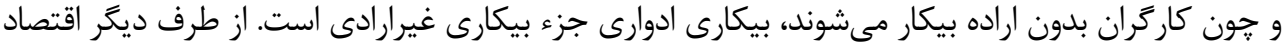

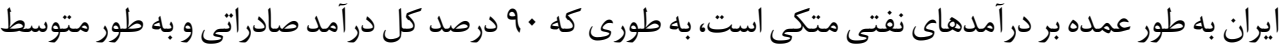


• ع درصد در آمدهاى دولت در بودجه سالانه را به خود اختصاص داده است. به دليل اينكه نفت و صادرات آن

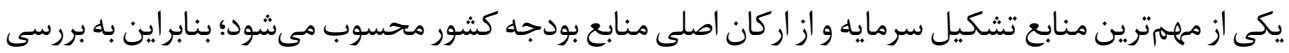

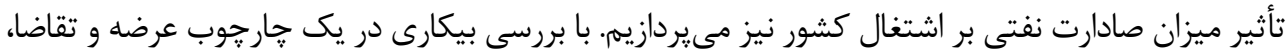

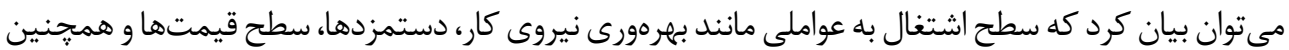

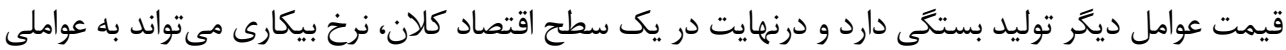

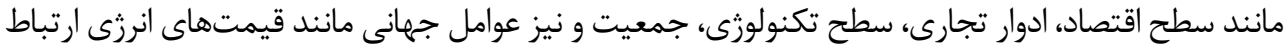

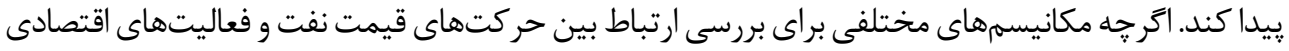

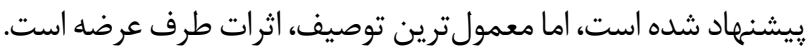

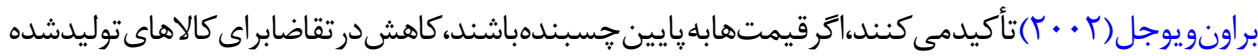

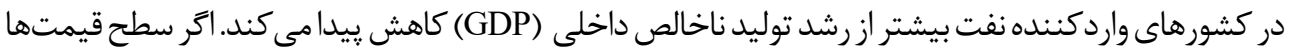

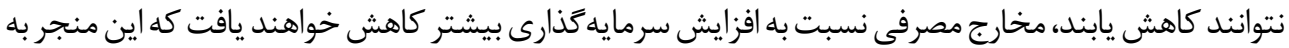

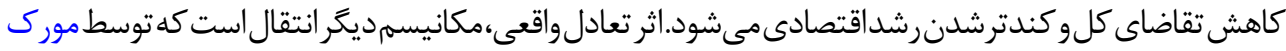

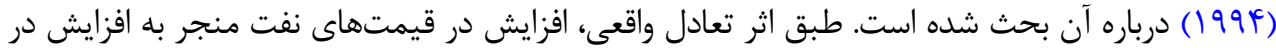

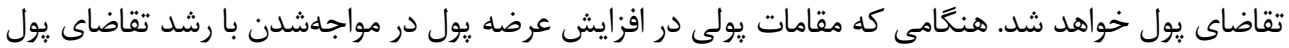

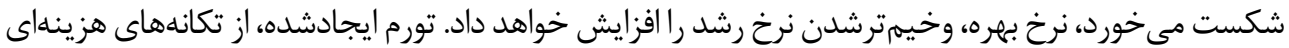

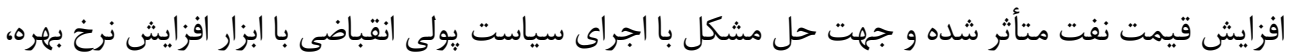

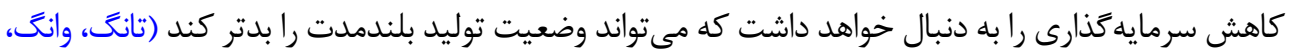

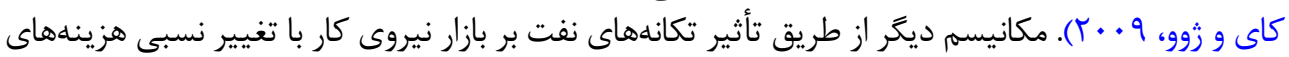

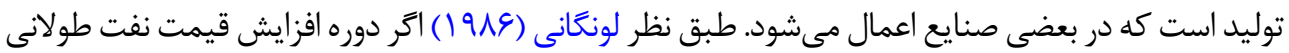

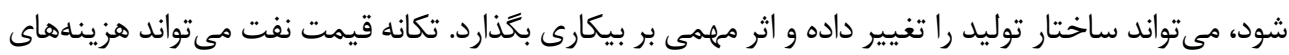

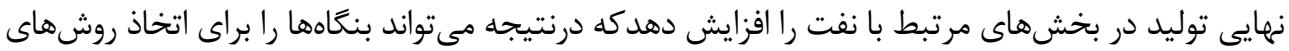

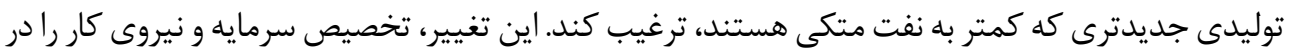

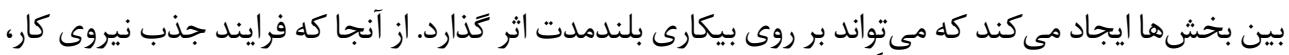

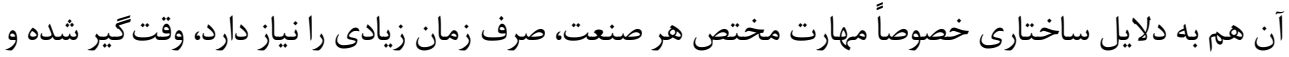

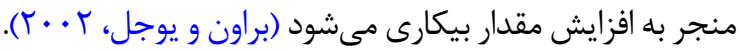

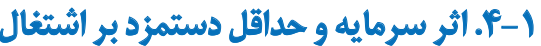

از يك نظر، تقاضا براى نيروى انسانى بستخى به اين دارد كه جُقدر بتوان بودجه به نيروى انسانى اختصاص داد.

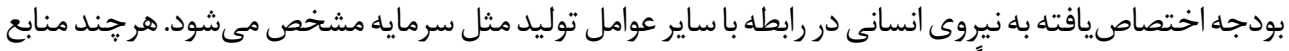

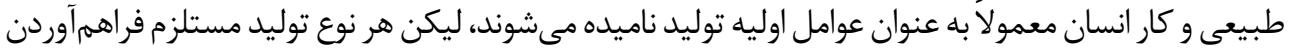

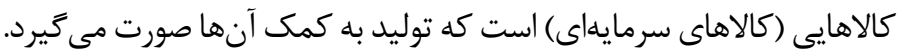
در اكثر كشورها، به منظور تحقق عدالت اجتماعى و حمايت از كارگرانى با تخصص و مهارت يايين، اقدام به 
تعيين حداقل دستمزد مىشود. در ايران نيز يس إز بِيروزى انقلاب و استقرار نظام جمهرورى اسلامى و با با تغيير

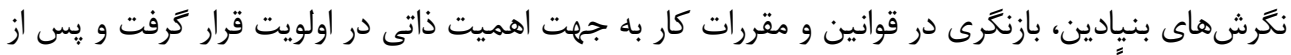

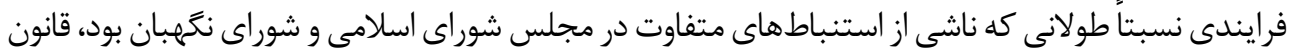

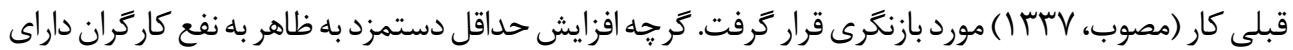

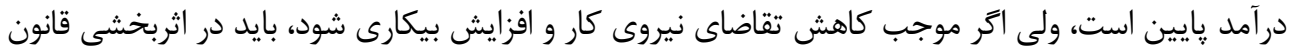

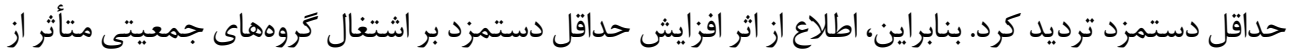

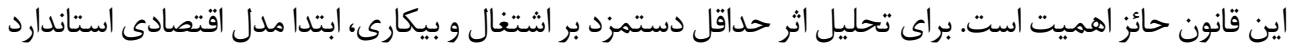

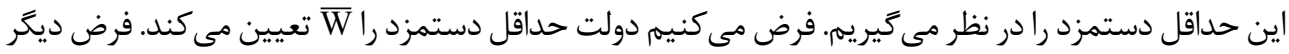

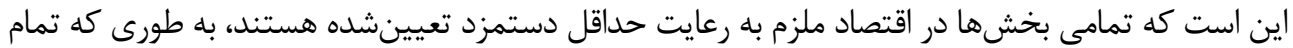

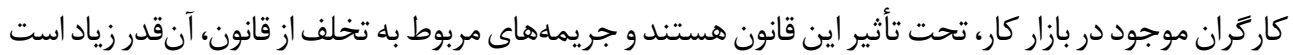

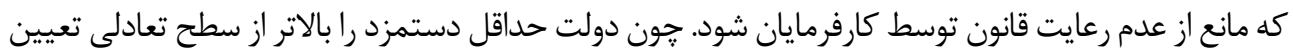

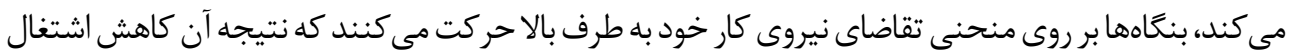

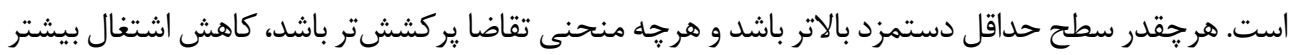

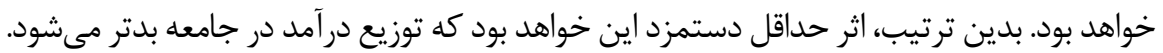

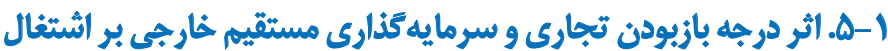

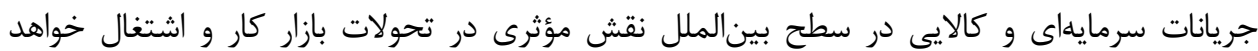

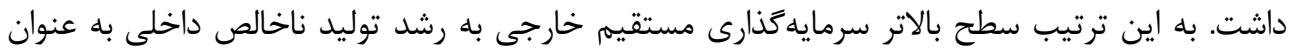

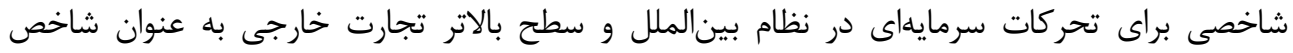

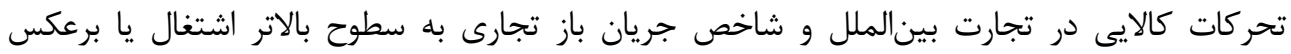

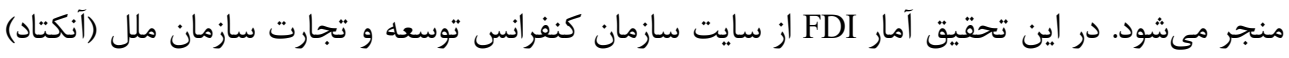
كرفته شده است.

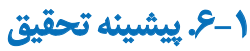

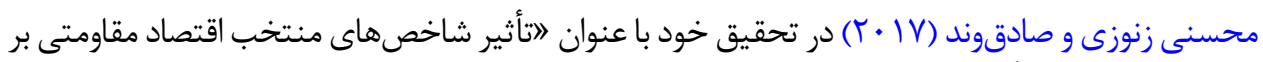

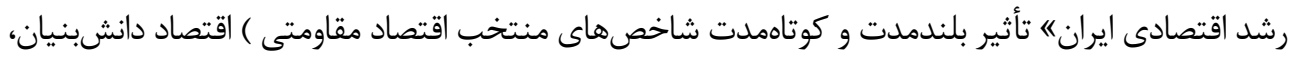

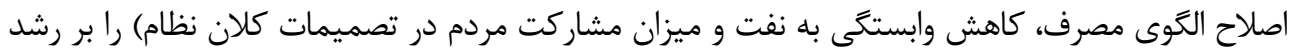

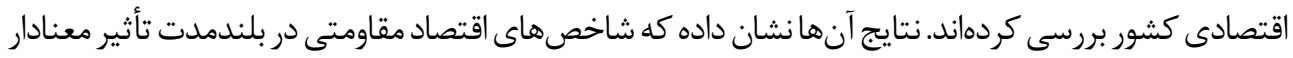

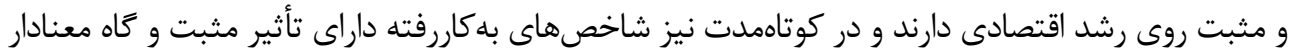

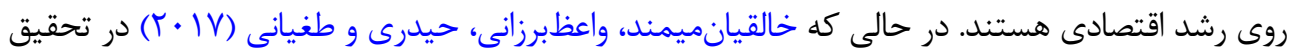

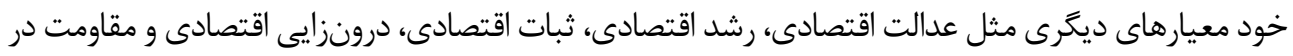

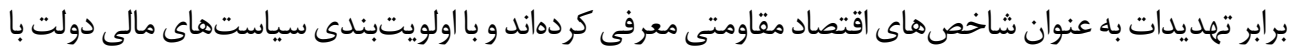




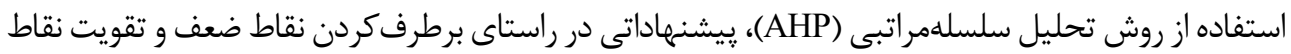
قوت اقتصاد براى رونق توليد ملى و رفع فقر و بيكارى دادهاند.

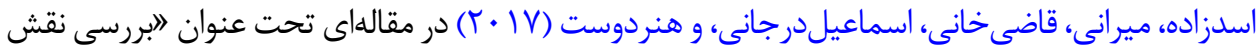

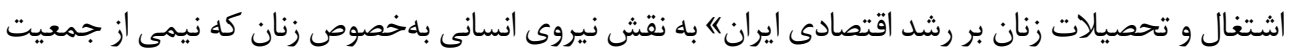

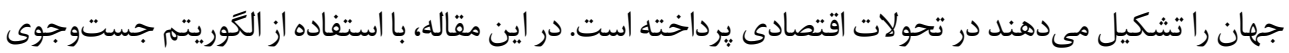

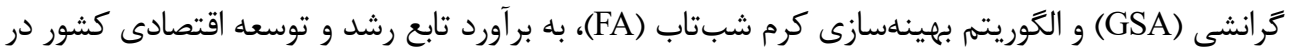

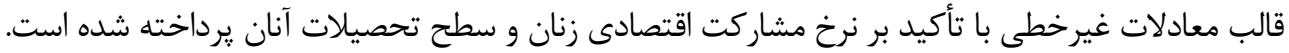

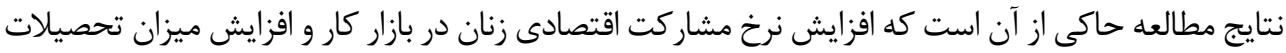

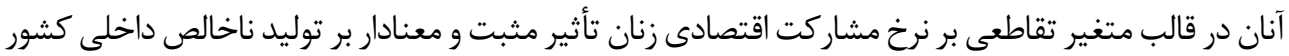

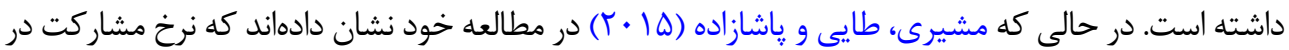

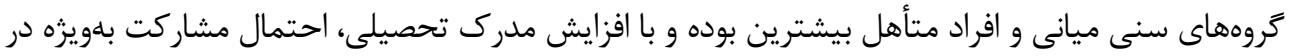
زنان افزايش يافته است.

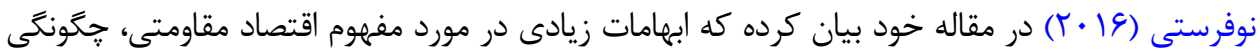

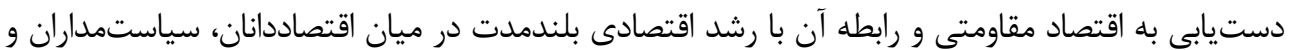

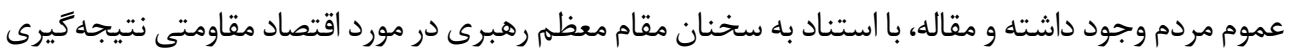

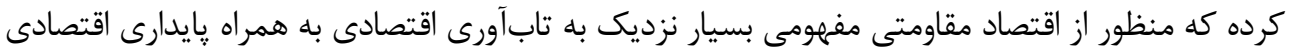

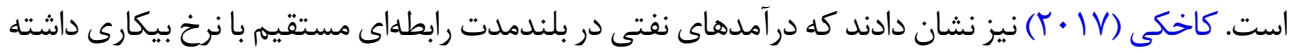

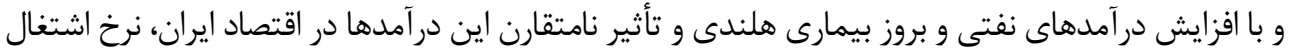

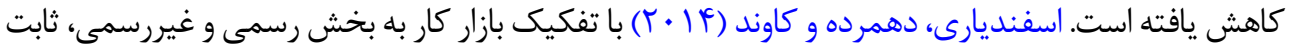

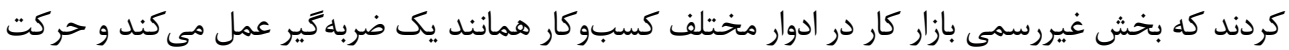

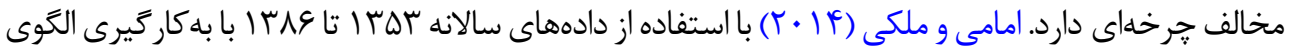

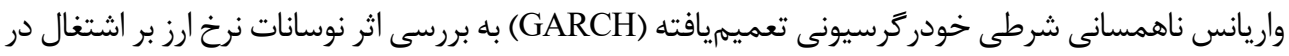

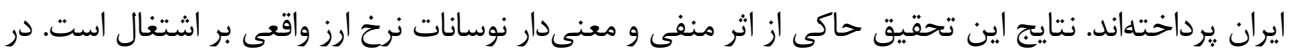

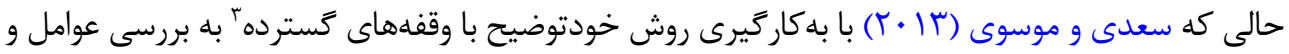

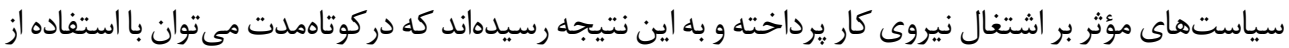

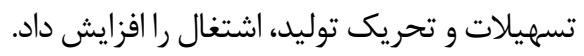

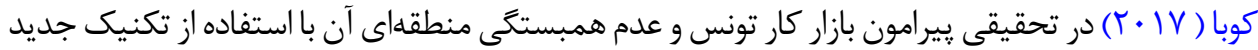

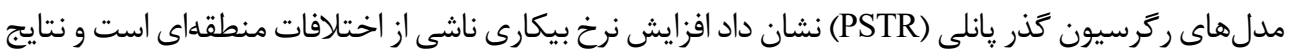

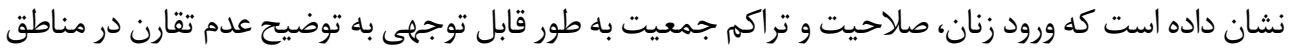




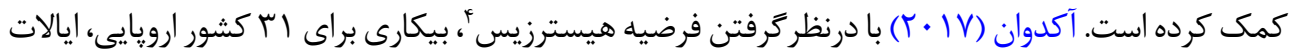

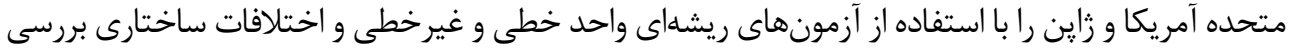

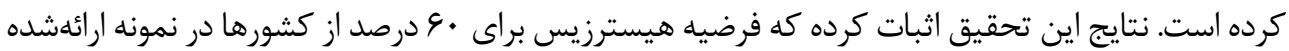

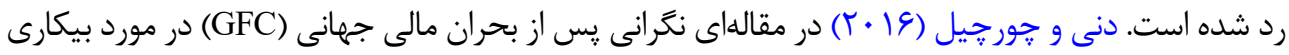

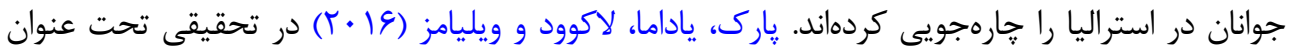

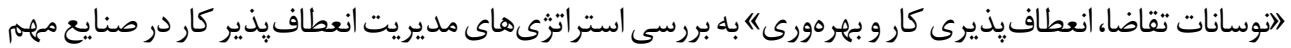

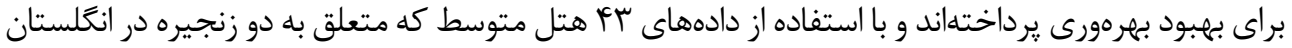

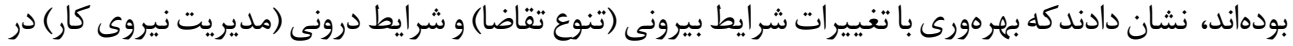

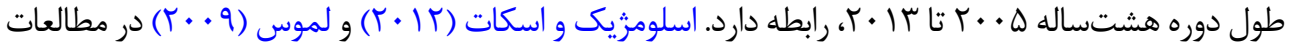

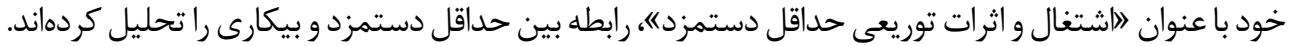

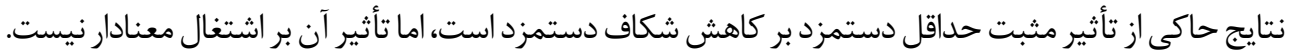
بنابراين با توجه به يِيشينه و اهميت موضوع كه مىتوان آن را هم در بيانات مقام معظم رهبرى و هم

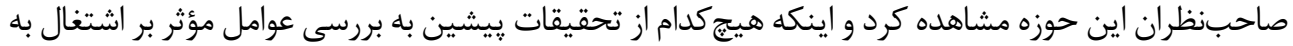

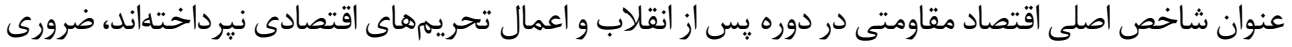

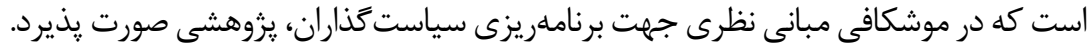

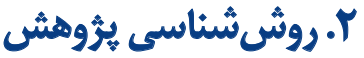

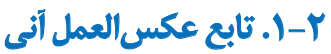

هر معادله خودرگرسيون را مى توان به فرايند ميانخين متحرك تبديل كرد. فرايند خودر گسيون بردارى نيز

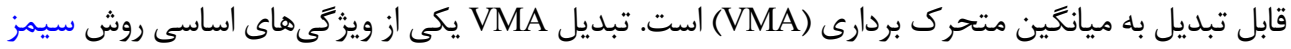

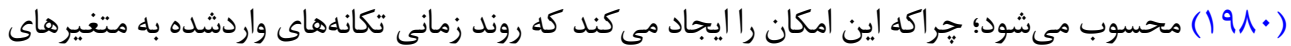

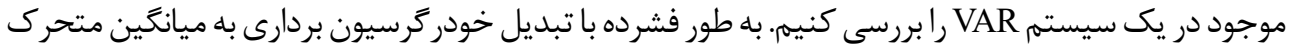

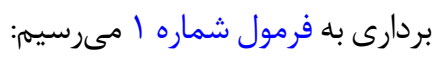

\section{1. $X_{t}=\mu+\stackrel{\ngtr a}{a} \varphi_{i=0}^{t} \varepsilon_{t-i}$}

تبديل ميانگين متحرك الگوى VAR ابزار بسيار مفيدى براى بررسى روابط متقابل ميان

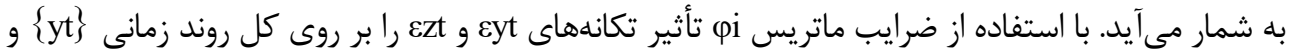
بر برسى مى كنيم. مجموعه ضرايب (Zt\}

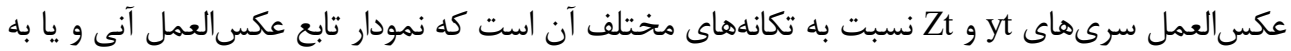

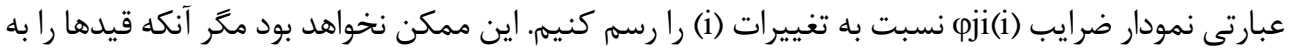

\section{Hysteresis}




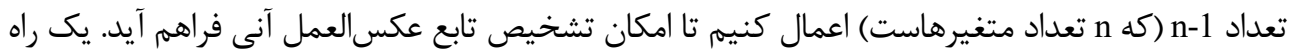

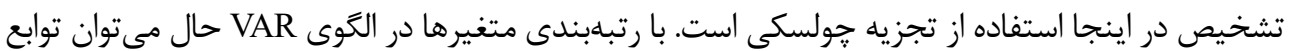

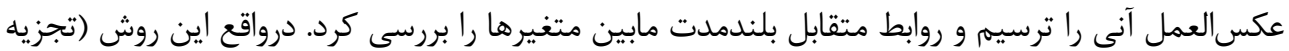

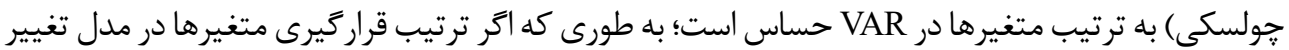

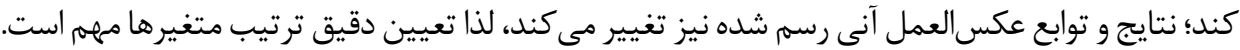

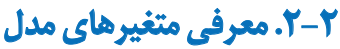

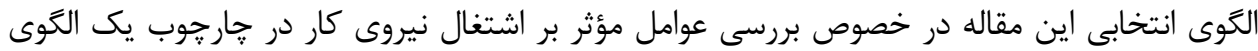

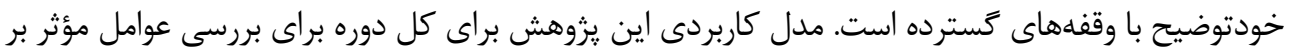

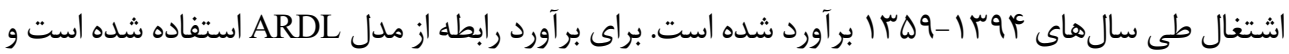

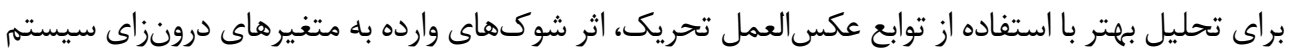

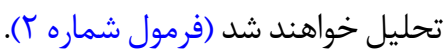

2. $L N L A B_{t}=C+\beta_{1} L N L A B_{t-n}+\beta_{2} L W A G E_{t-n}+\beta_{3} L G D P_{t-n}+\beta_{4} L C A P_{t-n}+\beta_{5} L R O I L_{t-n}+\beta_{6} L F D I_{t-n}+\beta_{7} L O-$ $P N_{t-n}+\varepsilon$

توليد ناخالص داخلاريتم تعداد شاغلين در كل كشور؛ LWAB

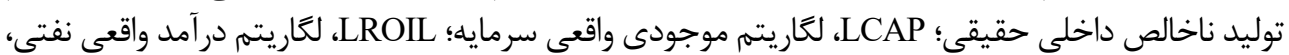
LFDI

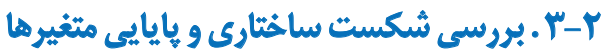

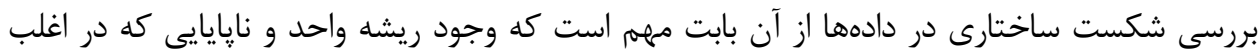

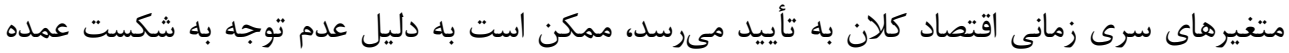

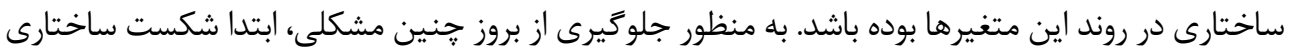

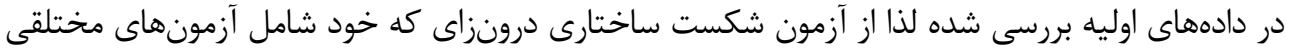

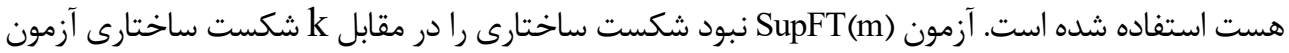

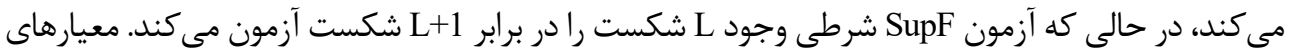
Sequentional , LWZ , BIC

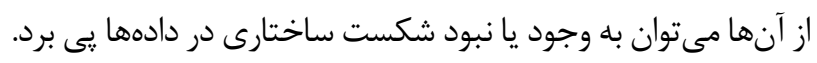

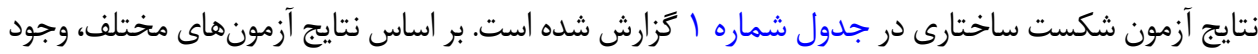

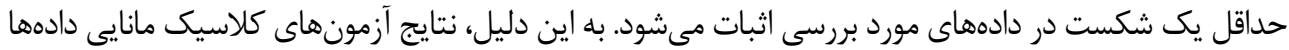

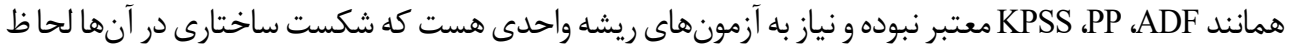


جدول ا. نتايج آزمون شكست ساختارى درونزاى باى - يرون

\begin{tabular}{|c|c|c|c|c|c|c|c|c|}
\hline \multirow{2}{*}{$\begin{array}{l}\frac{9}{3} \\
\frac{3}{2} \\
\frac{3}{3} \\
\frac{3}{3} \\
2 \\
2\end{array}$} & \multicolumn{7}{|c|}{ مقادير محاسبهشده } & \multirow[b]{2}{*}{ أزمونها } \\
\hline & كل كشاغلين & بازبودن & شرمايهكذارى & نورآمد & مورجودي & ناخالص & حستمزد & \\
\hline$N \Delta A$ & $r \cdot r q$ & IV/FY & $1 Q / / T$ & $10 / 9$. & $V /$. & $\varphi / \Delta$. & $r / m F$ & $\operatorname{SupF}_{T}(1)$ \\
\hline$V / T r$ & $1 . / 11$ & MT/\&D & $r / 19$ & WQ. & $11 / 9$. & g/ar & $\Delta / r$. & $\operatorname{SupF}_{T}(2)$ \\
\hline$\Delta / \vartheta$ & $R T / P$. & 19/Tr & $r \Delta / \Delta f$ & MT/VE & Q/AV & $r \cdot / q$. & $\mid \Delta / 18$ & $\operatorname{SupF}_{T}(3)$ \\
\hline p/qq & $f \Delta / N$ & MT/VD & MV/q. & $1 \& / N^{n}$ & $0 \cdot 18 P$ & $V / a$. & $\varphi \cdot / A r$ & $\operatorname{SupF}_{T}(4)$ \\
\hline- & $f$ & r & $f$ & $f$ & $f$ & r & f & $\begin{array}{l}\text { تعلداد شكست أزمون } \\
\text { SupF }\end{array}$ \\
\hline NQA & $r+/ \Delta \Delta$ & $\mid f / \Delta$ & $\mid w / A$. & $1 . / M$ & $\Delta / \Delta C$ & $F / \Delta$ & $r / T F$ & $\operatorname{SupF}_{T}(1 \mid 0)$ \\
\hline $1 . / 1 r$ & $11 / 9$. & m/r/r & $1 . / 199$ & $r / u$ & - & - & - & $\operatorname{SupF}_{T}(1 \mid 2)$ \\
\hline$M / 1 F$ & NAV & - & - & - & - & - & - & $\operatorname{SupF}_{T}(2 \mid 3)$ \\
\hline- & r & 1 & 1 & 1 & صقر & صقر & صقر & تعداد شكست آزمون \\
\hline - & r & $r$ & r & r & r & r & $r$ & تعداد شكست BIC \\
\hline- & $r$ & $r$ & $r$ & $r$ & r & 1 & 1 & تعداد شكست \\
\hline- & $\Delta$ & $\Delta$ & $\Delta$ & 1 & شكست & شكست & شكسب & تعداد شكست \\
\hline
\end{tabular}

شده باشد ـ بنابر اين از آزمون مانايى با دو شكست ساختارى درونزا استفاده شده است. K حداكثر تعداد وقفه بهينه

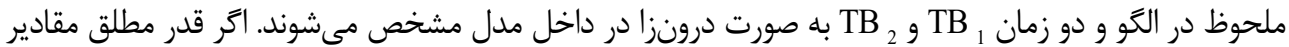

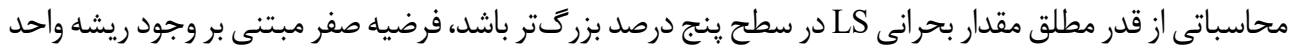

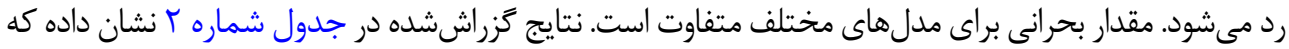

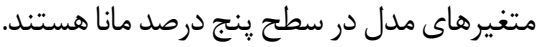
آزمون وايت و بروش ـ گَادفرى به ترتيب حاكى از نبود مشكل ناهمسانى واريانس و خودهمبستخى هستند. 
جدول r. آزمون ريشه واحد لي ـ استرازيكيج

\begin{tabular}{|c|c|c|c|c|c|c|}
\hline تئيجه مر سطح بنجح & 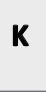 & $\mathrm{TB}_{2}$ & $\mathrm{~TB}_{1}$ & مدل & مقدار محاسبهشده & متغيرها \\
\hline $\mathrm{I}(0)$ & r & IrVA & Irepe & C & $-\Delta / \varphi$ & حداقل دستمزد حقيقى \\
\hline$I(0)$ & - & irev & (re. & C & $-9 / 1 V$ & توليد ناخالص داخلى حقيقى \\
\hline$I(0)$ & $\&$ & Irve & שאשו & A & $-r / / f$ & موجودى واقعى سرمايه \\
\hline$I(0)$ & r & $I r V \lambda$ & Iref & C & $-\Delta / A V$ & درأمد واقعى نفت \\
\hline$I(0)$ & $\varepsilon$ & Irve & WrF & C & $-g / \Delta F$ & سرمايهكذارى خارجى \\
\hline$I(0)$ & $\wedge$ & $\operatorname{Irr}$ & $17 \Delta 9$ & A & $-r / 8 \Delta$ & درجه بازبودن تجارى \\
\hline$I(0)$ & r & 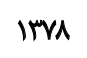 & Irge & C & - & تعداد شاغلين كل كشور \\
\hline
\end{tabular}

جدول r. آزمونهاى تشخيصى

\begin{tabular}{|c|c|c|}
\hline احتمال آماره & آماره & آزمونها \\
\hline.$/ 19$ & - lear & جاى برا \\
\hline$\cdot / \Delta V$ & $\mid r / 1 F$ & وايت \\
\hline$\cdot / \pi$ & $r / M P$ & بروش ـ كادفرى \\
\hline
\end{tabular}

1

مأخذ: محاسبات تحقيق

نتيجه آزمون جاك برا نيز نشان از نرمالبودن توزيع جزء اختلال ها دارد. نتايج آزمونهاى ييش گفتهه در جدول شماره ب ₹زارش شده است.

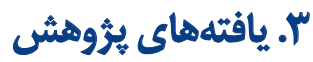

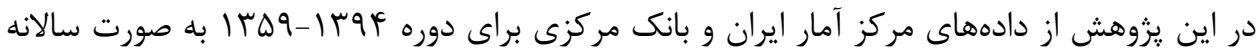

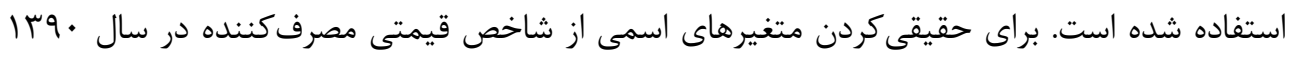

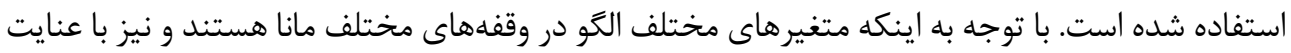

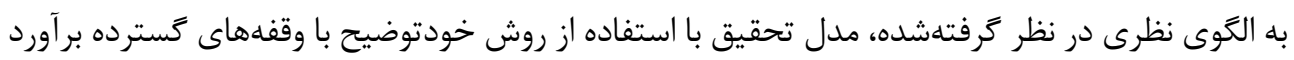

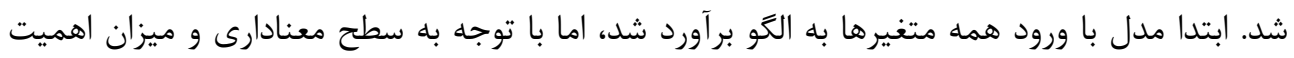

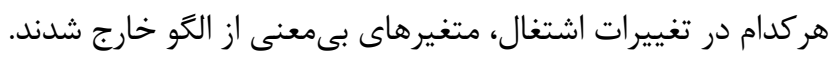


جدول F. برآورد التكوى يوياى كوتاهمدت اشتغال

\begin{tabular}{|c|c|c|c|c|}
\hline وضعيت معناداري & احتمال & $t$ & ضريب & متغير \\
\hline معنادار & .1. & r/AV & . /Va & LNLAB (-1) \\
\hline معنادار & .1. & $\Delta / I T$ & $V / \notin \Delta$ & $\operatorname{LNLAB}(-2)$ \\
\hline معنادار & I. & $m / \cdot \varphi$ &.$/ r q$ & LGDP \\
\hline ععنادار &.$/ . r$ & rise & I/TA & LGDP \\
\hline ليىمعنا &.$/ 19 q$ & $1 / \infty \Delta$ & .18 & LWA GE \\
\hline معنادار & .1. & $-r / T \Lambda$ & $-\cdot / \pi$ & LWA GE (-1) \\
\hline بيىمعنا & .1 .99 &.$- / 97$ & $-+/ F V$ & LWA GE (-2) \\
\hline معنادار &.$\ldots$ & $-9 / 97$ & $-+/ 1 r$ & LWA GE $(-3)$ \\
\hline معنادار & .1 .4 & $r / 4$ & VET & LROIL \\
\hline بي بعنا &.$/ 1 f$ & $-1 / \cdot \Delta$ & $-\cdot / r$ & LFDI \\
\hline معنادار & $.1 .0 \Delta$ & $r \% \wedge$ & $V \cdot 9$ & LFDI(-1) \\
\hline معنادار & .1. & $r(A)$ &.$/ 9$ & LFDI(-2) \\
\hline معنادار &.$/+P A$ & $P / V^{P}$ & $V / r 1$ & LOPNEN \\
\hline معنادار & .1. & $V / \cdot r$ & V/u & LOPNEN(-1) \\
\hline معنادار & .1. & $g / R T$ & $\mid r / \Delta q$ & $\mathrm{C}$ \\
\hline معنادار & $.1 \cdot 1$ & $\Delta / \cdot \Delta$ &.$/ \cdot r$ & TREND \\
\hline \multicolumn{5}{|c|}{$D W=1 / 9 Y$} \\
\hline \multicolumn{5}{|c|}{$\mathrm{R}^{2}=+/ 9 \Delta$} \\
\hline
\end{tabular}

براى تجزيه و تحليل از روش ARDL ، مبتنى بر تفسير سه معادله يوياه، بلندمدت ؤو تصـحيح خطالاستفاده

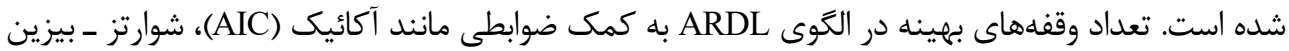
(HQC) تعيين مىشود. مقادير با وقفه متغير وابسته و مقادير با وقفه و جارى متغيرهاى (SBC)

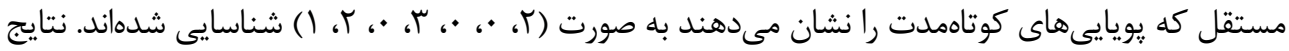

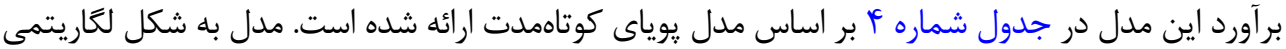

7. Error-Correction 
ارائه شده است. يس ضرايب حاصله ارائه كننده كشش^ (فرمول شماره ؟) هريك از متغيرها به تقاضاى نيروى كار هستند (فرمول شماره c).

3. $e_{x}=\left(\frac{\partial N L A B}{\partial X}\right) \times\left(\frac{\bar{X}}{\overline{N L A B}}\right)$

4. $L N L A B=12.59+0.75 * L N L A B_{t-1}+1.65 * L N L A B_{t-2}+0.29 * L G D P-0.33 * L W A G E_{t-1}$ $-0.12 * L W A G E_{t-3}+1.25 * L C A P+1.63 * L R O I L+1.09 * L F D I_{t-1}+0.9 * L F D I_{t-2}$ $+1.21 * L^{2 O P E N}+1.98 *$ LOPEN $_{t-1}+0.02 *$ TREND

در اين مدل ضريب تعيين هو درصد حاصل شده است؛ بدين معنا كه تغييرات متغيرهاى مستقل هو درصد

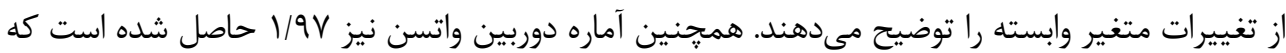

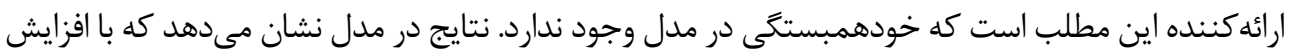

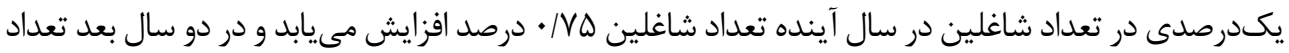

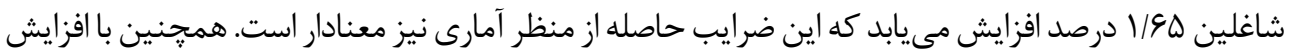

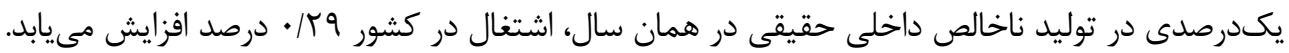

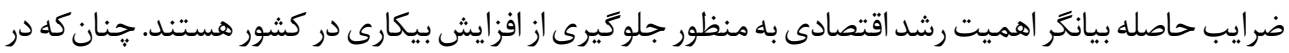

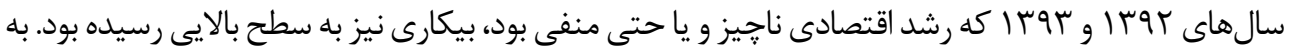

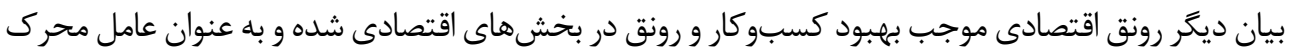

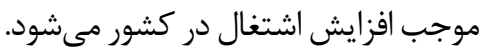

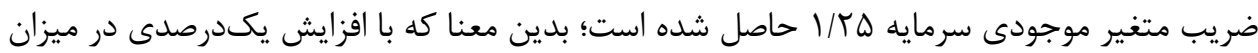

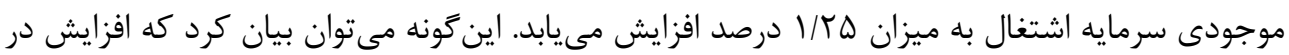

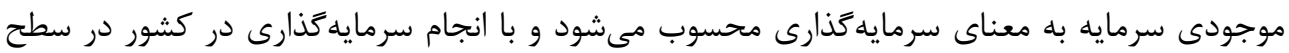

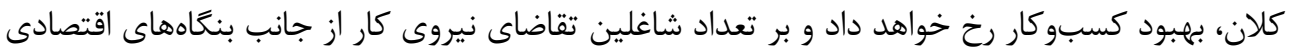

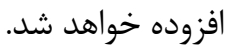

در مورد متغير حداقل دستمزد اعطايى به نيروى كار، مىتوان كفت كه دستمزد ارتباط مستقمى با ارزش

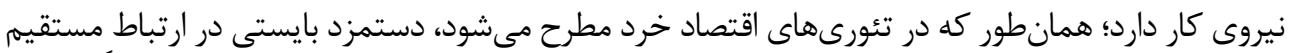

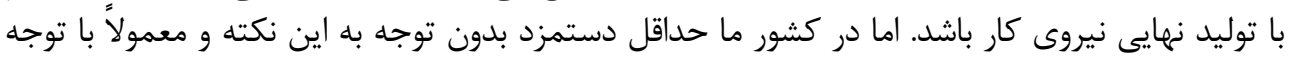

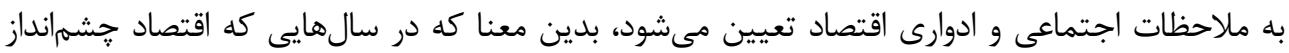

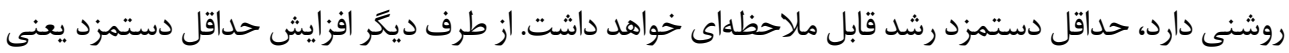

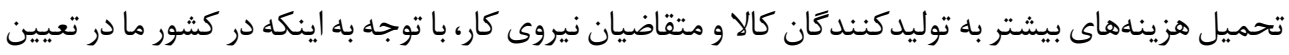

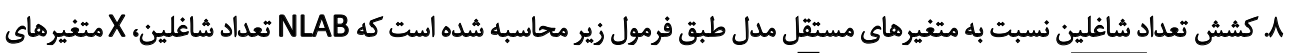
مستقل مدل، NLAB ميانكين تعداد شاغلين و 
حداقل دستمزد، معمولاً بدون توجه به ملاحظات اقتصادى طرف توليدكننده، تعيين مى شود، بنابراين افزايش

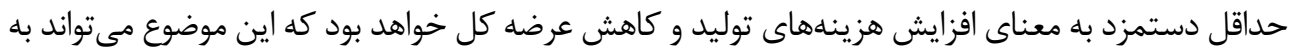
ورشكستكى توليد كنند

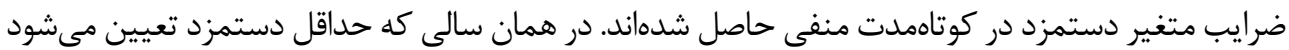

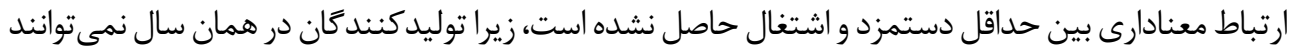

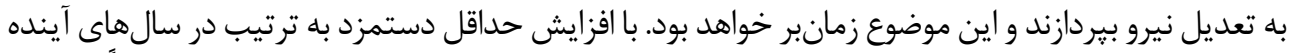

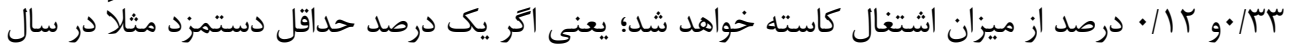

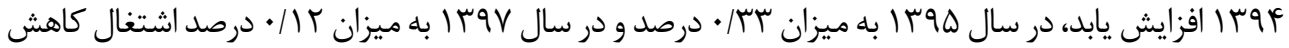

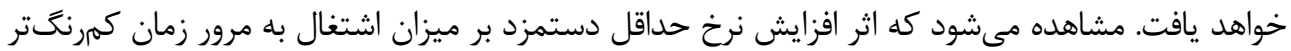
خواهد شد كه اثر اين شوك را بر ميزان اشتغال در ادامه خدود خواهيم سنجيد.

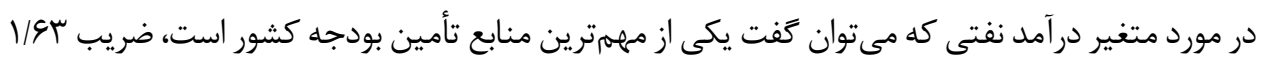

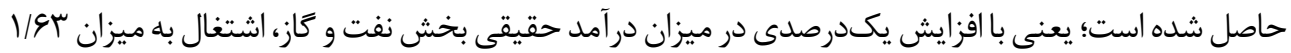

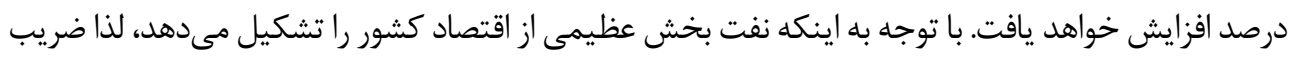

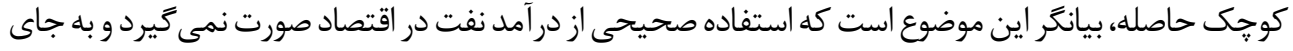

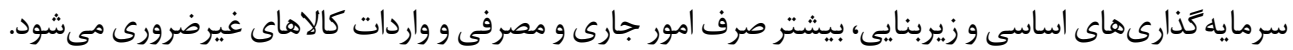
افزايش سرمايه گذارى مستقيم خارجى و بازبودن تجارى منجر به انتقال ارز بيشتر و يررونقتر شدن بازار توليد

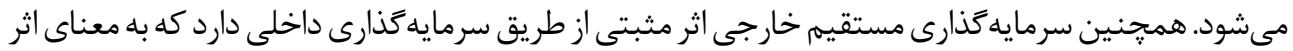

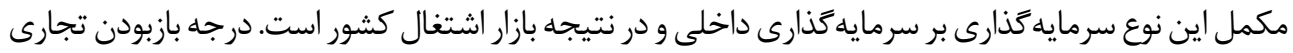

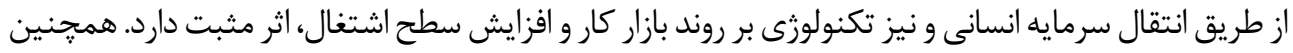

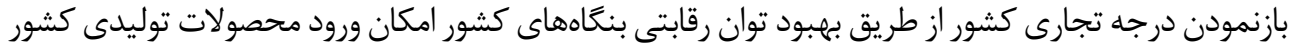

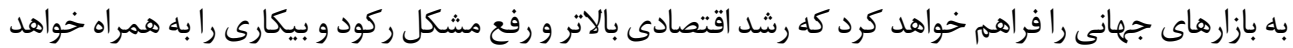

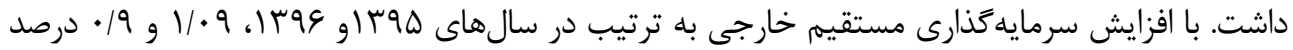
ميزان اشتغال افزايش يافته است.

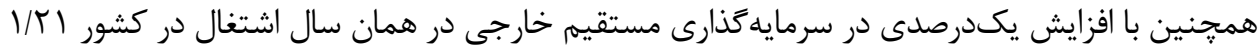

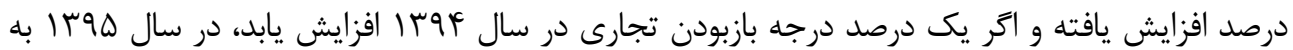

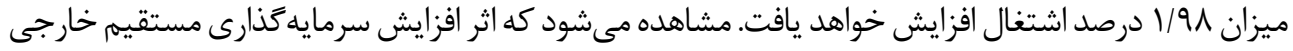

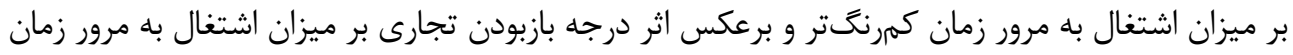

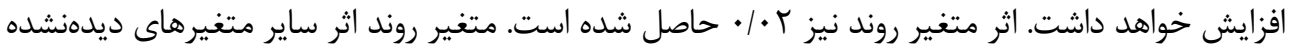

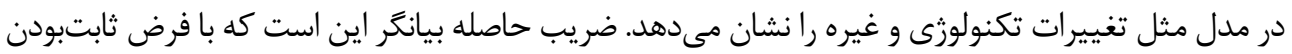

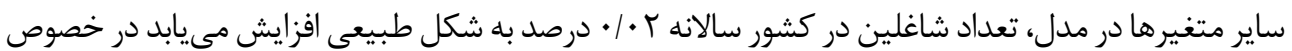

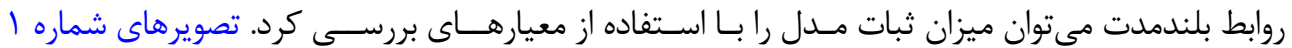




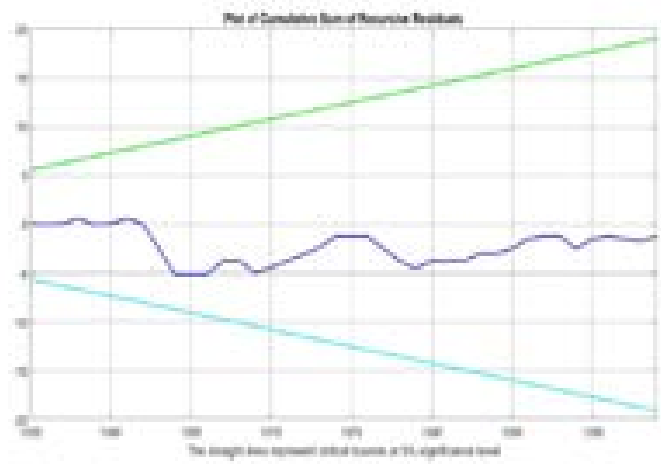

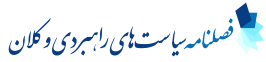
تصوير ا. آزمسون مجمـوع انباشـت بــــاندهاى عطفى (CUSUM)

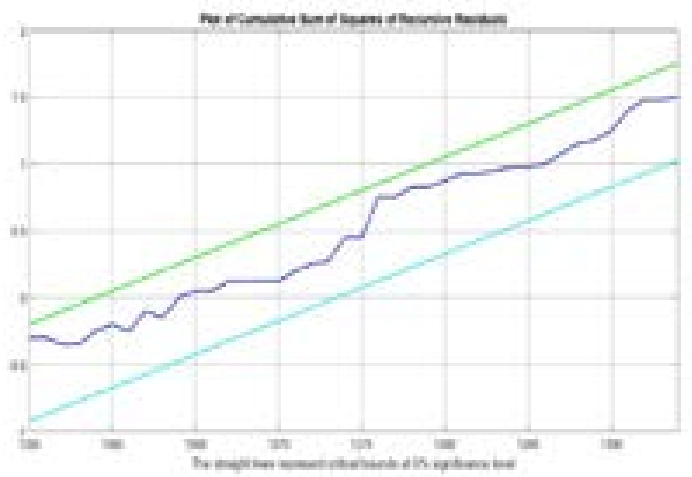

|ct

تصوير r. آزم-ون مجم-عقع مربعـات انباشـت بِماندهاى عطفى (CUSUMQ)

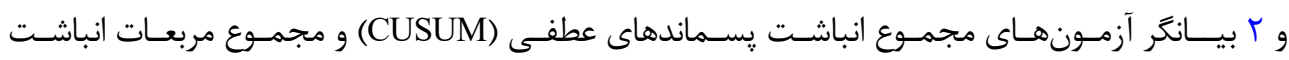
يسماندهاى عطفى (CUSUMQ) استـ

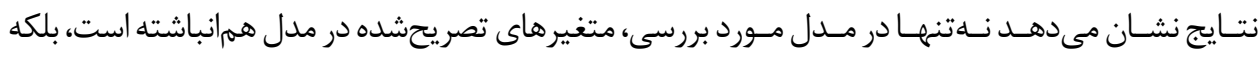

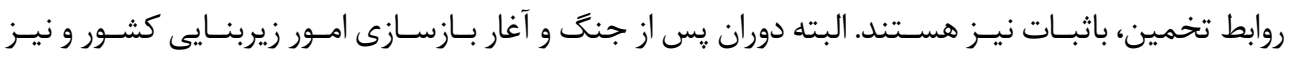

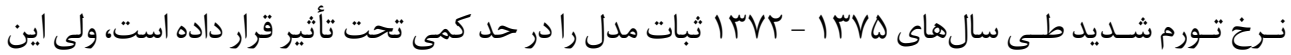

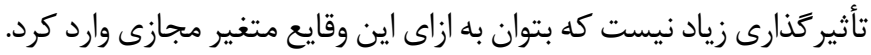

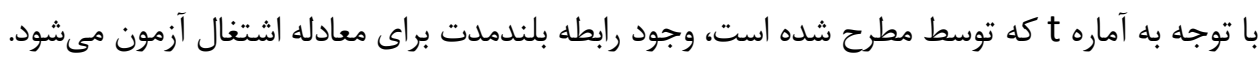

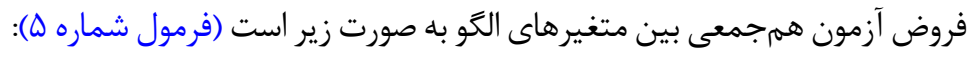


5. $\left[\begin{array}{rl}H_{0} & =\underset{i=\dot{f}}{\stackrel{P}{a}-1 \geq 0} \\ H_{1} & =\sum_{i=j}^{P} a_{i}-1<0\end{array}\right.$

فرضيه صفر بيانگر وجود رابطه بلندمدت است، جون شرط آنكه رابطه يوياى كوتاهمدت به سمت تعادل

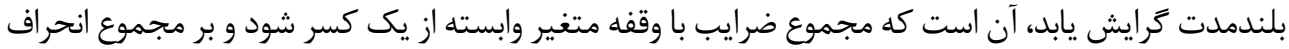

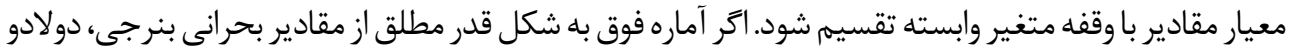

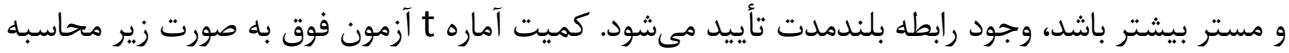
مىشود (فرمول شماره ؟):

6. $t=\frac{\sum_{i=1}^{p} \dot{a}_{i}-1}{\sum_{i=1}^{p} S \dot{a}_{i}}=\frac{\dot{a}_{i}-1}{S \dot{a}_{i}}=\frac{2.87-1}{0.4}=-4.59$

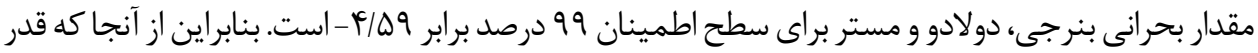

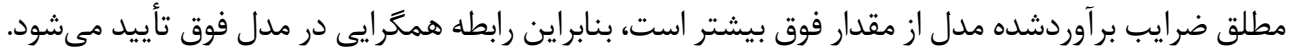

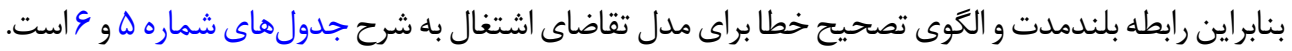

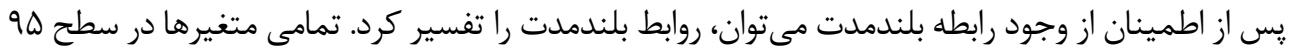
درصد معنى دار هستند.

نتايج نشان مى دهد توليد ناخالص داخلى، درآمدهاى نفتى، سرمايهگذارى مستقيم خارجى، بازبودن

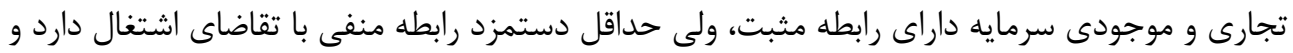

جدول هـ نثايج بهدست آمده از برآورد الكوى بلندمدت مدل اشتغال

\begin{tabular}{|c|c|c|c|c|}
\hline معنادارى & اجتمال & $\mathbf{t}$ & ضريب & متغير \\
\hline معنادار &.$/ 4 I$ & -r/qr & $-1+1 \Delta$ & LWAGE \\
\hline معنادار & $\%$ & NAq & $V \cdot r$ & LGDP \\
\hline معنادار & I.Mr & $r / v q$ & ع & LROIL \\
\hline معنادار & $1+4 \Delta$ & $r / \cdot \Lambda$ &.$/ 1$ & LFDI \\
\hline معنادار & $1 / p q$ & $|/ \lambda|$ & .198 & LOPEN \\
\hline معنادار & $.1+$ & $N U$ & .18 & LCAP \\
\hline
\end{tabular}


جدول و. نتايج حاصل از برآورد التوى تصحيح خطاى مدل اشتغال

\begin{tabular}{|c|c|c|c|c|}
\hline معثادارى & احتمال & $\mathbf{t}$ & ضريب & متغير \\
\hline معنادار & $+1 .$. & $f / R$ & .1 .1 & $\operatorname{LNLAB}(-1)$ \\
\hline معنادار & $.1 . r$ & $-r / 91$ &.$- / \Delta s$ & LWA GE (-1) \\
\hline معنادار & +1. & $s / N$ & $V \cdot r$ & $\operatorname{LGDP}(-1)$ \\
\hline بيىمنا &.$/ 91$ & . Irq & $.1 \cdot 1$ & LROIL (-1) \\
\hline معنادار & .1 .4 & $1 / u$ & - /ar & LFDI $(-1)$ \\
\hline بي معنا &.$/ N \Delta$ & $1 / \cdot 1$ & $V / \& \Delta$ & LOPEN $(-1)$ \\
\hline معنادار & .10 & $11 / 9$ &.$M$ & $\operatorname{LCAP}(-1)$ \\
\hline معنادار & $.1+1$ & $-F / T R$ & $-+/ \Delta \Delta q$ & ECM (-1) \\
\hline $\mathrm{R}^{2}=\stackrel{\sim}{ } \mathrm{W}$ & \multicolumn{2}{|c|}{$D W=\pi T \Delta F / T$} & \multicolumn{2}{|c|}{$F=\wedge \Delta \| / N$} \\
\hline
\end{tabular}

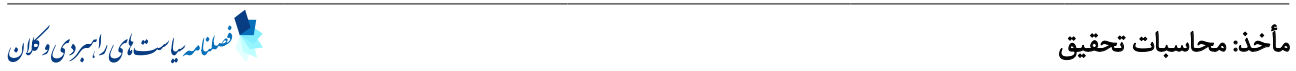

نشان مى دهد حداقل دستمزد در بلندمدت اثر منفى و كاهنده، بر سطح اشتغال دارد. در ادامه براى بررسى اينكه تعديل عدم تعادلهاى كوتاهمدت در اشتغال به سـمت تعـادل بلندمدت به

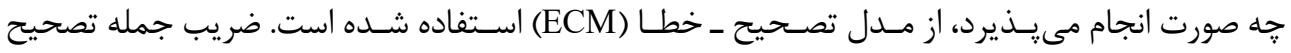

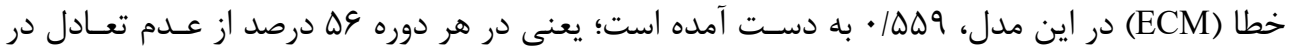

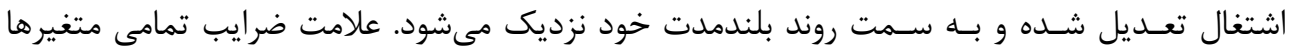

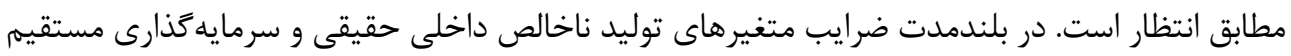

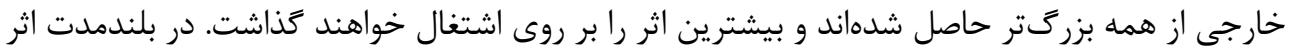

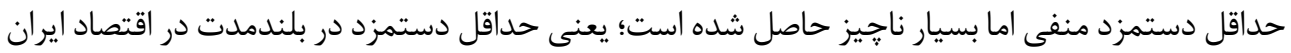

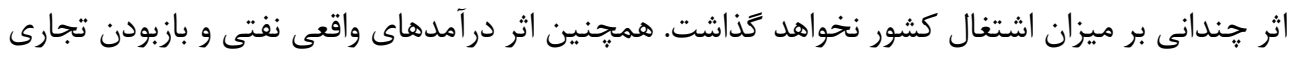

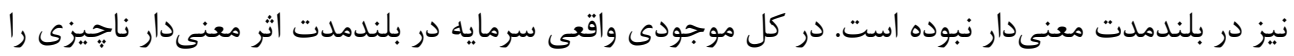
بر اشتغال خواهد كذاشت.

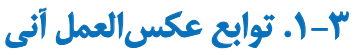




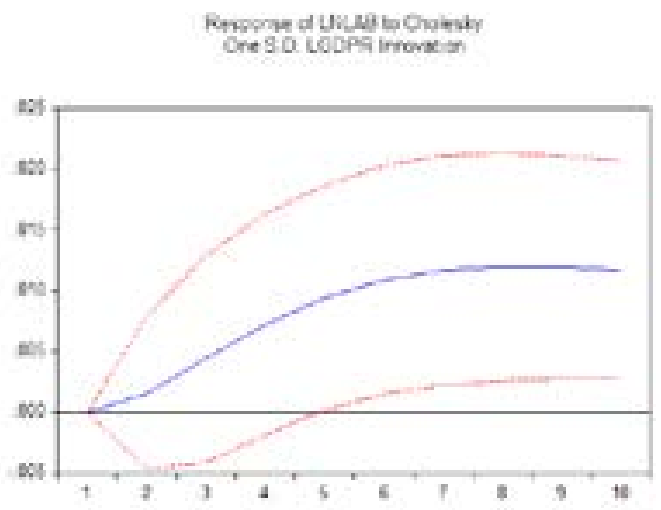

|ct

تابع عكسالعمل درواقع مطالعه زمانبندى شوكهاى اقتصادى است. مطالعه شوكها و زمانبندى آنها

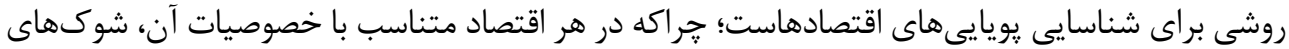

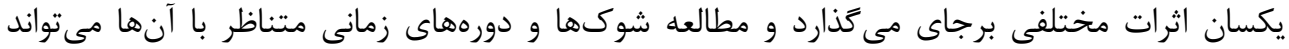

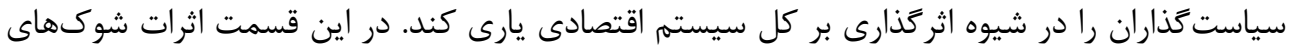

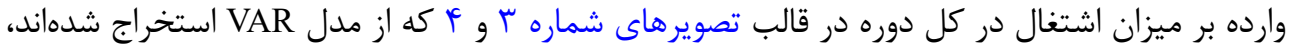

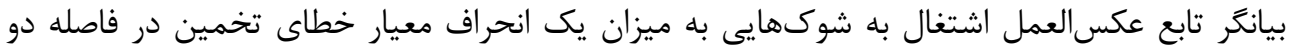

Response of LNLAB to Cholesky

One S.D. LCAPR Innovation

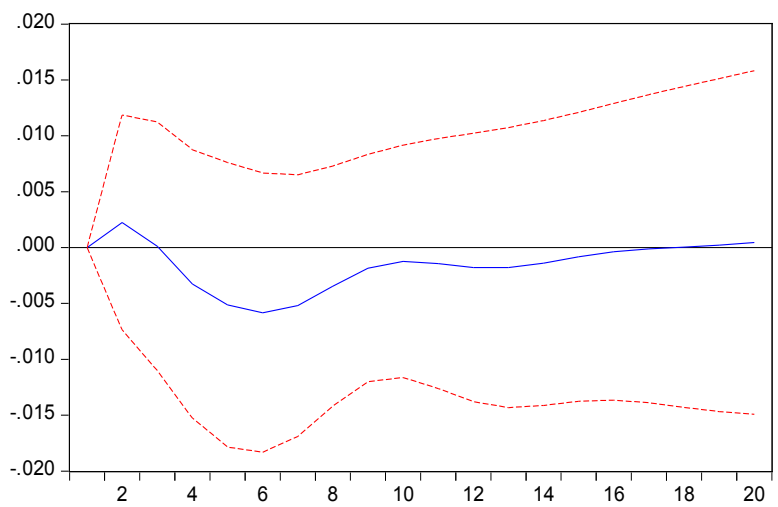

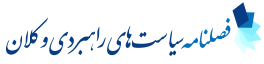

تصوير F. واكنش اشتغال به تكانه موجودى واقعى سرمايه (مأخذ: محاسبات تحقيق) 
Response of LNLAB to Cholesky

One S.D. LWAGER Innovation

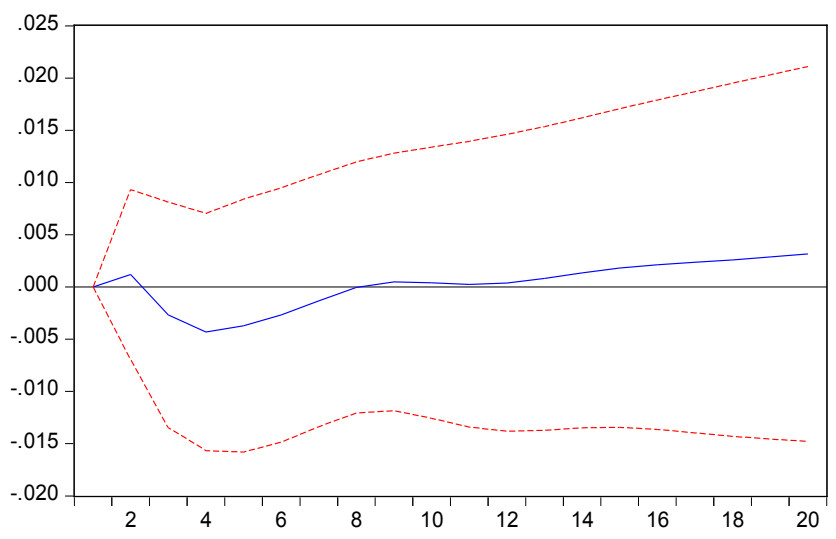

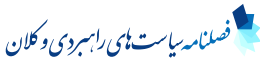

تصوير هـ واكنش اشتغال به تكانه حداقل دستمزد (مأخذ: محاسبات تحقيق)

انحراف معيار است. همانطور كه ديده مىشود آثار برخى شوكها حتى بعد از • ب دوره نيز باقى مىماند. در تصويرهاى شماره ه و و محور افقى، سال هايى است كه متغير وابسته به شوك در متغير مستقل واكنش را

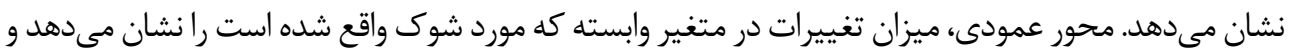

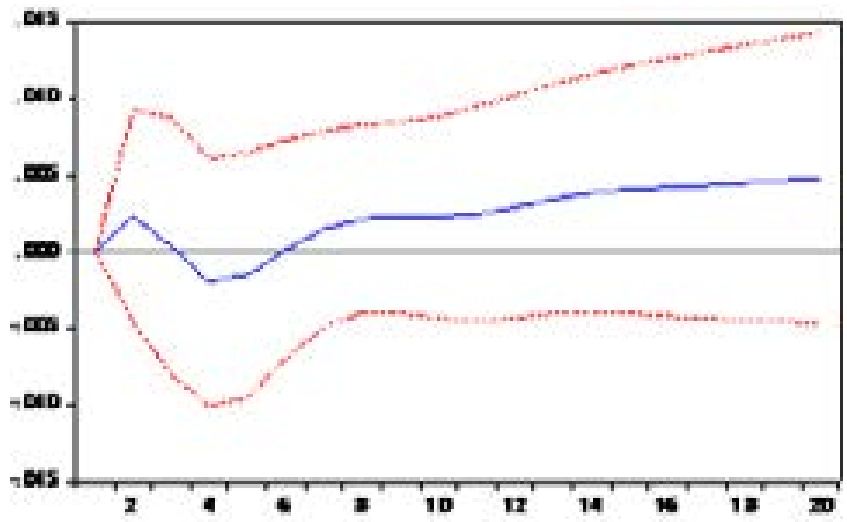

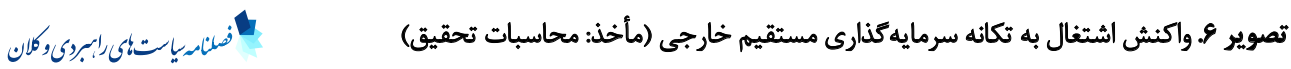
Respons of LNLAB to Cholesky one S.D. LFDI Inovation 
خود نمودار هم تغييرات در طول زمان را در ميان فاصله دو انحراف معيارى تغييرات ارائه مى كند. اثر شوك وارده

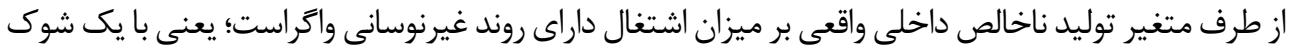

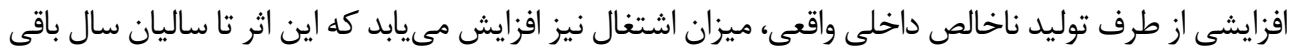

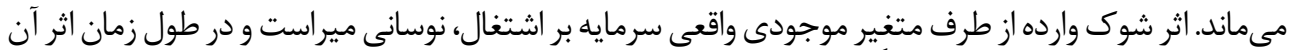

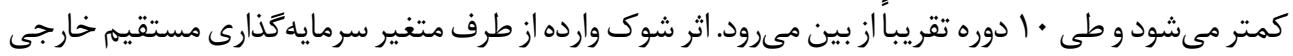

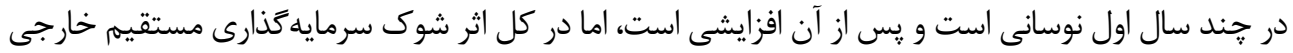

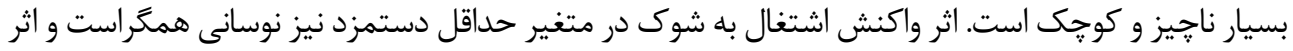

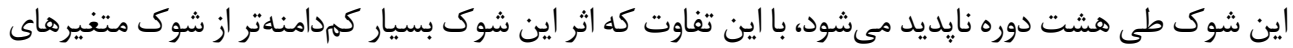

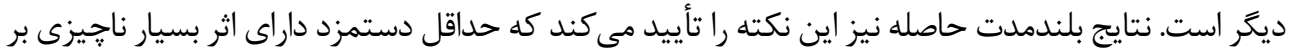

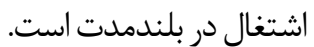

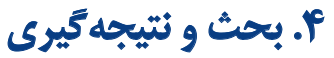

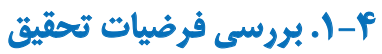

بر اساس مدل اقتصادسنجى ARDL مشخص شد كه ميزان حداقل دستمزد تعيينشده از سواري

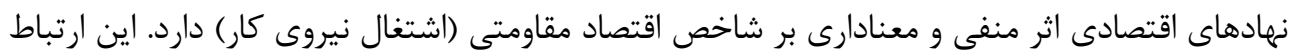

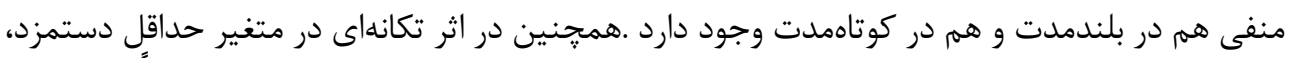

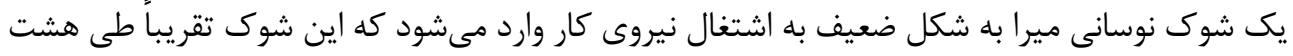

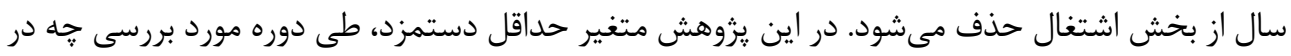

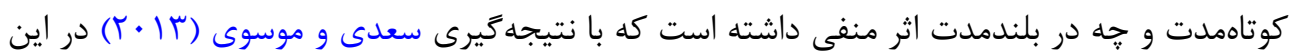

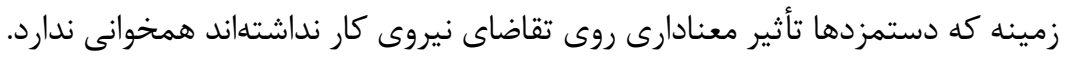

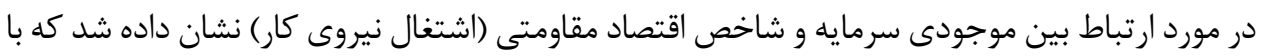

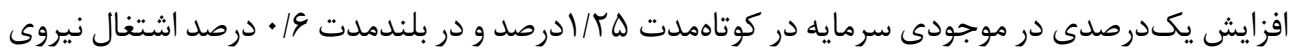

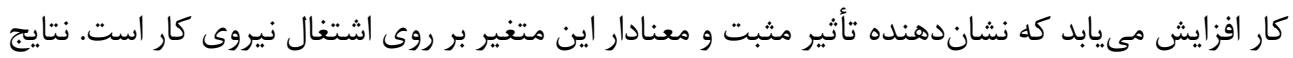

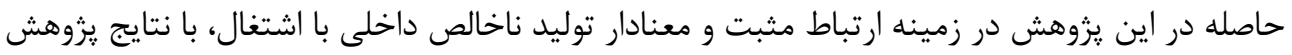

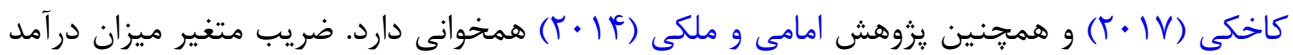

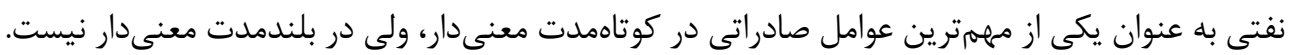

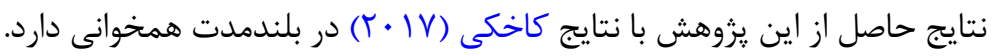

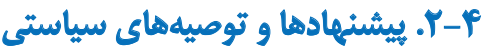

درمجموع مى توان گَفت كه نقش عوامل متغيرهاى توليد ناخالص داخلى حقيقى و سرمايه كذارى مستقيم

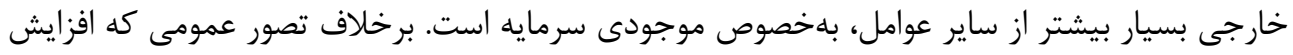


حداقل دستمزد را امرى مطلوب و مثبت مىداند، بررسى حاضر، نقش افزايش حداقل دستمزد را موجب

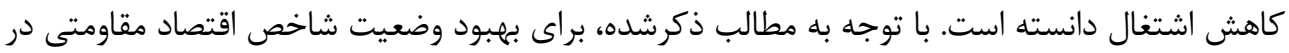

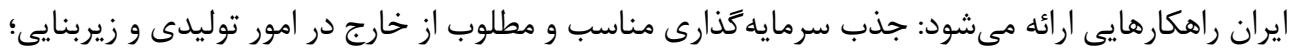

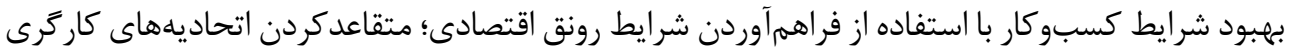

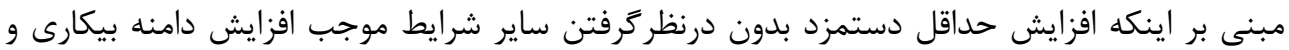

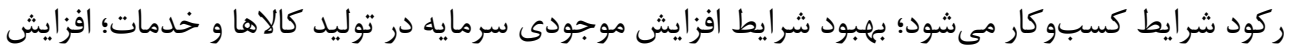

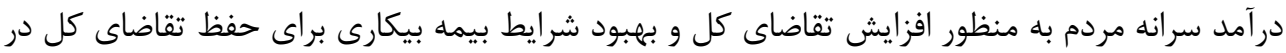
شرايط مطلوب.

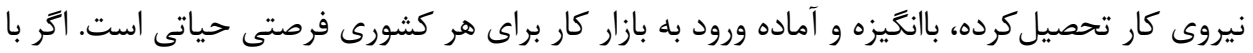

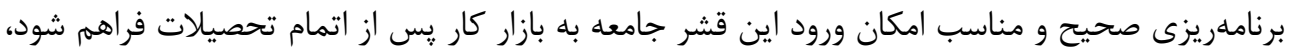

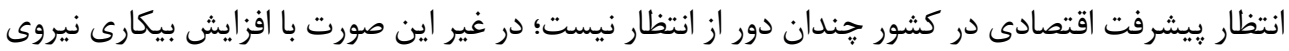

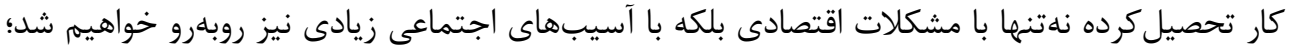

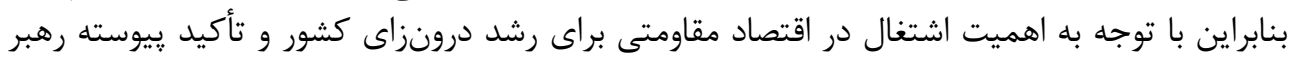

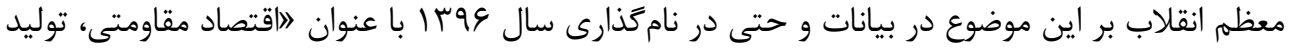

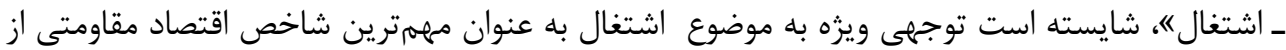
سوى همخان صورت گيرد.

ملاحظات اخلاقى

يميروى از اصول اخالاق هيخوهش

همه اصول اخلاقى در اين مقاله رعايت شده است.

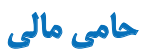

حامى مالى اين يزوهش دانشخًاه آزاد اسلامى واحد ابهر بوده است.

مشُشاركت نويسندكَان

با توجه به اينكه مقاله يك نويسنده داشته است، نگارش تمام بخشهاى مقاله برعهده ايشان بوده است.

تعارض منافُ

نويسنده اعلام مى كند كه هيجزَنه تعارض منافع در خصوص انتشار اين مقاله وجود ندارد. 


\section{تشكر و قدرداني}

به اين وسيله از تلاشها و زحمات ارزشمند و صادقانه جناب آقاى دكتر حميدرضا ميرزائى در زمينه پيشبرد و اتمام اين تحقيق سياسكَزارى مى كنهم. 


\section{References}

Akdoğan, K. (2017). Unemployment hysteresis and structural change in Europe. Empirical Economics, 53, $1415-40$. [DOI:10.1007/s00181-016-1171-8]

Asadzadeh, A., Mirani, N., Ghazikhani F, Esmail Darjani, N., \& Honardoust, A. (2017). [Investigating the role of employment and education of women on economic growth in Iran: Gravitational search algorithm and Firefly algorithm approach (Persian)]. Women in Development \& Politics, 15(3), 359-81. [DOI:10.22059/JWDP.2017.225995.1007138]

Brown, S. P. A., \& Yücel, M. K. (2002). Energy prices and aggregate economic activity: An interpretative survey. The Quarterly Review of Economics and Finance, 42(2), 193-208. [DOI:10.1016/S1062-9769(02)00138-2]

Denny, L., \& Churchill, B. (2016). Youth employment in Australia: A comparative analysis of labour force participation by age group. Journal of Applied Youth Studies, 1, 5-22. https://findanexpert.unimelb.edu.au/scholarlywork/1198473

Emami, K., \& Maleki, E. (2014). [The effect of exchange rate volatility on employment in Iran (Persian)]. Journal of Financial Economics (Financial Economics and Development), 8(26), 95-112. http://ecj.iauctb.ac.ir/article_512786.html

Esfandyari, M., Dahmardeh, N., \& Kavand, H. (2014). [Dual labor market in a dynamic stochastic general equilibrium model of Iran (Persian)]. The Economic Research, 14(1), 217-38. https://ecor.modares.ac.ir/article-18-10347-fa.html

Kajitani, Y., \& Tatano, H. (2009). Estimation of lifeline resilience factors based on empirical surveys of japanese industries. Earthquake Spectra, 25(4), 755-76. [DOI:10.1193/1.3240354]

Kakhaki, S. S. (2017). [The impact of oil revenue on employment rate in Iran (Persian)] [MSc. thesis]. Mashhad: Ferdowsi University of Mashhad. https:/ganj-old.irandoc.ac.ir/articles/874446

Khaleghian Meymand, A., Vaez Barzani, M., Heidari, M. R., \& Toghyani, M. (2017). [Fiscal policy in moqawama economy strategies (Persian)]. Islamic Economy, 17(66), 13-45. http://eghtesad.iict.ac.ir/article_26572.html

Koubaa, Y. (2017). Tunisian labor market and regional heterogeneity: Application of PSTR model. International Journal of Regional Development, 4(1), 51-81. [DOI:10.5296/ijrd.v4i1.10299]

Lemos, S. (2009). Minimum wage effects in a developing country. Labour Economics, 16(2), 224-37. [DOI:10.1016/j.labeco.2008.07.003]

Loungani, P. (1986). Oil price shocks and the dispersion hypothesis. The Review of Economics and Statistics, 68(3), 536-9. [DOI:10.2307/1926035]

Mohseni Zonouzi, S. J, \& Sadeghvand, B. (2017). [The effects of selected moqawama economy indices on Iran's economic growth (Persian)]. Islamic Economy, 17(67), 39-63. http://eghtesad.iict.ac.ir/article_28689.html

Mork, K. A. (1994). Business cycles and the oil market. The Energy Journal, 15, 15-38. [DOI:10.5547/ISSN0195-6574-EJ-Vol15NoSI-3]

Moshiri, S., Taee, H., \& Pashazadeh, H. (2015). [Labour force participation in Iran the role of education and gender (Persian)]. The Economic Research, 15(2), 49-72. http://journals.modares.ac.ir/article-18-11700-fa.html

Mottaghi, L. (1998). [Analysis and estimation of employment demand in Iran (1971-2006) (Persian)]. The Journal of Planning and Budgeting, 3(3), 39-63. http://jpbud.ir/browse.php?a_code=A-10-4-445\&slc_lang=fa\&sid=fa

Noferesti, M. (2016). [Resilient economy and how it could be achieved (Persian)]. The Macro and Strategic Policies, 4, $157-68$. http://www.jmsp.ir/article_42054.html 
Park, S., Yaduma, N., Lockwood, A. J., \& Williams, A. M. (2016). Demand fluctuations, labour flexibility and productivity. Annals of Tourism Research, 59, 93-112. [DOI:10.1016/j.annals.2016.04.006]

Sadi, M. R., \& Mousavi, M. H. (2013). [An investigation of factors and policies affecting labor force employment in Iranian economy (Persian)]. Economics Research, 13(49), 177-98. http://joer.atu.ac.ir/article_912.html

Sims, C. A. (1980). Macroeconomics and reality. Econometrica, 48(1), 1-48. [DOI:10.2307/1912017]

Slonimczyk, F., \& Skott, P. (2012). Employment and distribution effects of the minimum wage. Journal of Economic Behavior \& Organization, 84(1), 245-64. [DOI:10.1016/j.jebo.2012.03.005]

Tang, D., Wang, Y., Cai, J. \& Zhao, R. (2009). Effects of exogenous application of plant growth regulators on the development of ovule and subsequent embryo rescue of stenospermic grape (Vitis vinifera L.). Scientia Horticulturae, 120(1), 51-7. [DOI:10.1016/j.scienta.2008.09.018] 